\title{
The effect of glutamate-gated chloride current on the excitability of a Purkinje cell: a modeling study
}

\author{
Shiwei Huang ${ }^{1 *}$, Erik De Schutter ${ }^{1,2}$ \\ From Twentieth Annual Computational Neuroscience Meeting: CNS*2011 \\ Stockholm, Sweden. 23-28 July 2011
}

Purkinje neurons express, in high abundance, a glutamate gated chloride channel commonly known as the Excitatory Amino Acid Transporter subtype 4 (EAAT4). EAAT4 belongs to the family of glutamate transporters, which in mammalian nervous system is responsible for clearing synaptic glutamate [1]. Studies of these transporters in heterogeneous expression systems demonstrated that in addition to glutamate transport, the binding of glutamate to the transporter activates a chloride current through the transporter with properties liken that of a channel and which is functionally independent from the transport process [2].

The role of the chloride channel in glutamate transporters is only known for the EAAT subtype 5 (EAAT5). On rod bipolar cell axon terminals, EAAT5 activation by glutamate results in membrane hyperpolarization, which consequently inhibits terminal glutamate release [3]. Whether the chloride channel of EAAT4 has a physiological role in Purkinje neurons remains unknown. A synaptic model was developed to determine conditions in which the chloride channel of EAAT4 could influence Purkinje neuron function and whether these conditions are physiologically relevant.

The model comprises a single compartment with uniform distribution of AMPA receptors and EAAT4. The EAAT4 model is based on a 16-state kinetic model of EAAT2 [4] using reaction rates of EAAT4 measured in [5]. AMPA receptor conductance and absolute permeability of EAAT4 were parameterized for adjusting their respective current amplitudes. The model reproduced the EPSC and EAAT4 channel currents evoked in a
Purkinje neuron by parallel fiber stimulation under conditions similar to those used in [5]. The result serves as a basis for investigating the effects of the EAAT4 chloride current on Purkinje neuron excitability and intracellular chloride concentration.

\section{Author details}

${ }^{1}$ Computational Neuroscience Unit, Okinawa Institute of Science and Technology, Okinawa 904-0411, Japan. ${ }^{2}$ Theoretical Neurobiology, University of Antwerp, B-2610 Antwerpen, Belgium.

Published: 18 July 2011

References

1. Tzingounis AV, Wadiche Jl: Glutamate transporters: confining runaway excitation by shaping synaptic transmission. Nat Rev Neurosci 2007, 8(12):935-947.

2. Vandenberg RJ, Huang S, Ryan RM: Slips, leaks and channels in glutamate transporters. Channels 2008, 2(1):51-58.

3. Veruki ML, Morkve SH, Hartveit E: Activation of a presynaptic glutamate transporter regulates synaptic transmission through electrical signaling. Nat Neurosci 2006, 9(11):1388-1396.

4. Bergles DE, Tzingounis AV, Jahr CE: Comparison of coupled and uncoupled currents during glutamate uptake by GLT-1 transporters. J Neurosci 2002, 22(23):10153-10162.

5. Wadiche Jl, Tzingounis AV, Jahr CE: Intrinsic kinetics determine the time course of neuronal synaptic transporter currents. Proc Natl Acad Sci 2006, 103(4):1083-1087.

doi:10.1186/1471-2202-12-S1-P154

Cite this article as: Huang and De Schutter: The effect of glutamategated chloride current on the excitability of a Purkinje cell: a modeling study. BMC Neuroscience 2011 12(Suppl 1):P154.

\footnotetext{
* Correspondence: shiweihuang@oist.jp

${ }^{1}$ Computational Neuroscience Unit, Okinawa Institute of Science and

Technology, Okinawa 904-0411, Japan

Full list of author information is available at the end of the article
}

(c) 2011 Huang and De Schutter; licensee BioMed Central Ltd. This is an open access article distributed under the terms of the Creative 